\title{
Development and implementation of Portuguese smart distribution system
}

\author{
C. Gouveia, D. Rua, F.J. Soares*, C. Moreira, P.G. Matos, J.A. Peças Lopes \\ INESC TEC - INESC Technology and Science (formerly INESC Porto) and Faculty of Engineering, University of Porto, Portugal
}

\section{A R T I C L E I N F O}

\section{Article history:}

Received 1 February 2014

Received in revised form 22 May 2014

Accepted 9 June 2014

Available online 27 June 2014

\section{Keywords:}

Smart grid implementation

Automation

Control

Communications

InovGrid

REIVE

Smart Grids and Electric Vehicle Laboratory

\begin{abstract}
A B S T R A C T
The consolidation of smart grids is inevitably related with the development and actual implementation of different functionalities envisioned for future electric grids. This paper presents the major implementations of smart grid projects in Portugal, which resulted from a close collaboration between academia and industry. An overview of the entire development process is presented culminating with the real implementation of the developed concepts. The architectures and functional models are presented as the initial step in defining the management and control functionalities for future smart distribution networks. The intermediate step consists in validating the advances introduced by smart grids. Simulation tools are emphasized considering both electrical and communications aspects. Finally, a laboratory infrastructure implemented to be used as a real test bed and a pilot deployed in a large city are presented in the end. The associated learning has provided relevant information for future developments.
\end{abstract}

() 2014 Elsevier B.V. All rights reserved.

\section{Introduction}

Electric power systems are facing significant changes due to the increasing levels of distributed energy resources penetration. This new scenario affects the way how power systems, in particular distribution grids, are managed, ranging from technical issues related with operation and planning to economic and regulatory aspects. In this context, the Smart Grids (SG) vision has been pointed out as a possible solution to exploit available infrastructures, while maximizing distributed energy resources integration and extending consumers' participation in the overall electricity value chain [1].

To a large extent, small scale distributed energy resources - Electric Vehicles (EV), microgeneration units, energy storage devices and flexible loads - are widely spread and usually connected to low voltage (LV) distribution networks, requiring the implementation of local control solutions to mitigate technical problems resulting from their integration. Simultaneously, LV distributed energy resources can be aggregated in order to globally provide new functionalities to system operators, based on microgrid (MG) [2] and multi-microgrid (MMG) [3] concepts. The implementation of such

* Corresponding author at: INESC TEC, Campus da FEUP, Rua Dr. Roberto Frias, 4200-465 Porto, Portugal. Tel.: +351 22209 4212; fax: +351 222094050.

E-mail address: fsoares@inescporto.pt (F.J. Soares). concepts enables the coordinated control and management of distributed energy resources, exploiting their flexibility. The level of control required to achieve this goal requires the utilization of costcompetitive technologies and new communication systems. The deployment of smart meters (SM) is also an important factor that can be seen as a way of pushing forward the development of the SG concept by providing the infrastructure to support advanced control and management functionalities within the distribution system [4]. This is the pathway followed by the Portuguese Distribution System Operator (DSO), EDP Distribuição, by supporting two nationwide SG projects: InovGrid and REIVE.

The InovGrid project main purpose was to develop an advanced metering system and define a set of functionalities to endow the distribution grid with the necessary intelligence to tackle the paradigm change in the electric industry [5]. In this project, a strong focus was devoted to microgeneration management and control in LV grids, while providing customers the necessary conditions to access new services. The project was supported by a conceptual architecture, followed by the functional and technical specification of the different controllers. The specification was dully supported through advanced system studies extensively exploiting simulation tools to better demonstrate the potential benefits of the control solutions. The specifications of InovGrid project were rolled-out in Évora, in a pilot site designated as InovCity, where devices, functionalities and the control architecture were tested in a real-world scenario, providing both a test bed and a demonstration site. 


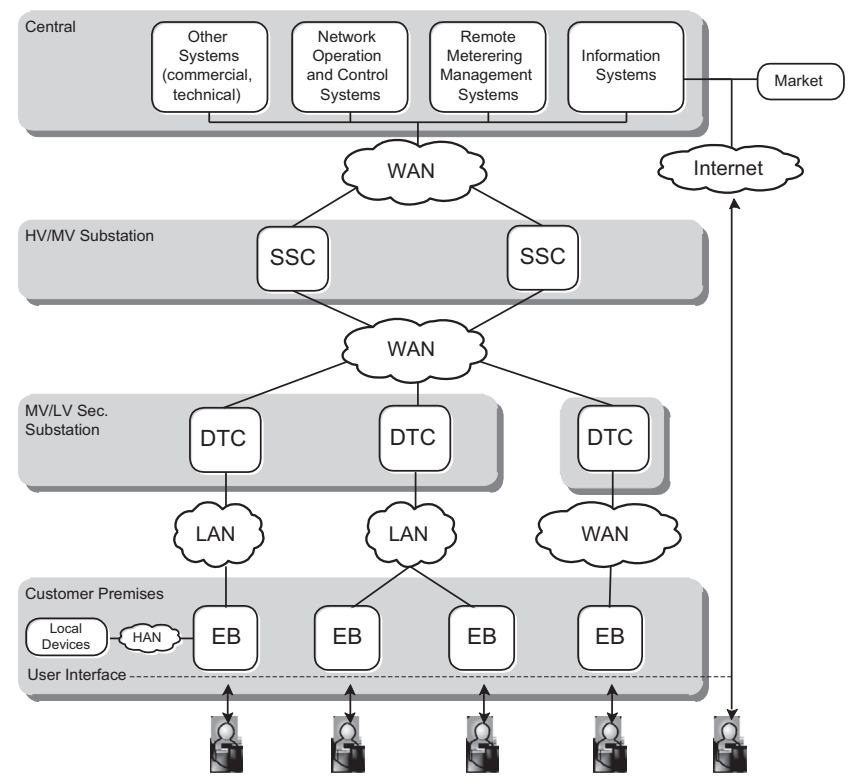

Fig. 1. InovGrid advanced architecture.

The REIVE project was headed by INESC Porto and aimed at developing a technological framework towards the integration of EV in Portuguese distribution grid [6]. This project is intrinsically an extension of InovGrid, with a specific target regarding the identification, specification and testing of innovative solutions within the SG concept to allow an enhanced technical and market integration of microgeneration and EV. Within this framework, a laboratory infrastructure was designed and implemented to develop and test solutions and prototypes, promoting an active and intelligent grid management in scenarios characterized by a progressive integration of microgeneration units and EV.

This paper presents the main outcomes of both InovGrid and REIVE project, namely in what concerns the technical and market reference architectures, control and management functionalities and main results. The implementation and validation of the developed concepts in both laboratory environment and in InovCity pilot site are also presented.

\section{Functional architectures and models of Portuguese SG initiatives}

One of the most relevant outputs of both projects was the definition of a conceptual architecture for technical and market operation of electric power systems exploiting concepts such as distributed management and control and remote energy management.

\subsection{InovGrid}

The reference architecture of InovGrid was inspired in the hierarchical control developed and associated with the MG concept, developed under MICROGRIDS and MOREMICROGRIDS European projects [7]. Fig. 1 illustrates the InovGrid reference architecture where besides the traditional distribution management system (DMS), three additional levels and management entities were defined: the energy box (EB), the distribution transformer controller (DTC) and the smart substation controller (SSC). The EB corresponds to the SM installed in the customer premises, equipped with control, management and communications modules. It supports active and reactive energy metering, maximum power in a configurable time period, voltage metering and remote tariff and contracted power management.
The DTC is responsible for receiving and processing the data collected from all the EB connected downstream. It will also receive information from the central systems and distribute the information or the resulting control signals to the downstream EB. Besides remote metering, the DTC can also integrate functionalities for the supervision, management and control of LV distribution feeders, similarly to the central controller of a MG. The SSC installed in high voltage/MV substations, in an intermediate layer between the central systems and the DTC, will be responsible for managing and controlling the different devices within a MV network and coordinate the operation of downstream LV networks.

A communications infrastructure was also defined to support the reference architecture, thus enabling the data exchange among entities. In the access networks the preferred technologies were narrowband PLC and GPRS. In the backhaul networks broadband technologies like ADSL were chosen, being GPRS used as alternative. For local control support, ZigBee was the main candidate for a fast and low-cost deployment of a communications network for monitoring and control.

\subsection{REIVE}

The main focus of REIVE project was to promote technical and market integration of renewables and $\mathrm{EV}$, while avoiding grid reinforcements. The EV is envisioned as a flexible resource, providing both load flexibility and storage capacity. Given this controllability a set of new grid supporting functionalities were envisioned. Within this context, developing and specifying new market entities becomes essential, as the expected integration of EV and microgeneration units increases. The architecture defined under REIVE project is represented in Fig. 2. In the technical operation framework the InovGrid distribution network operation architecture was extended to enable the integration of EV in the operation of the system, through the specification of a new low level entity the energy box for the electric vehicle (EB-EV). The EB-EV integrates specific functionalities to allow the management of the EV charging process and provides support for related services.

The main innovation of the new architecture is the market structure where an aggregator entity was defined to provide relevant market representation [20]. The hierarchic market structure was designed to interact with the control counterpart, with a Regional Aggregation Unit interacting with clusters of EV at MV through the SSC, whereas a MG Aggregation Unit interacts with the LV EV owners through the DTC. Communications solutions were designed and developed considering the main operation requirements in order to support the different control schemes and the market integration.

\subsection{Advanced functionalities for distribution networks management and control}

The functionalities envisaged by the InovGrid reference architecture were (and are still being) implemented in the InovCity test site (see Section 4.1), being deployed in three main phases. In the first one, several remote services were implemented, such as remote metering, consumer remote connection/disconnection, remote modification of the contracted power, tariff setup, tampering alarms, MV switching etc. Other functionalities tailored for LV consumers were also incorporated in the first phase, such as promotion of customer awareness and their engagement in energy efficiency programmes (in-home displays were provided by the DSO to some clients, providing real-time information of their power consumption and generic energy efficiency advices). The second stage was essentially focused on the public lighting. Old lamps were replaced by a highly efficient public lighting system, based on LED luminaries with automatic dimming and remote control by the DTC. 


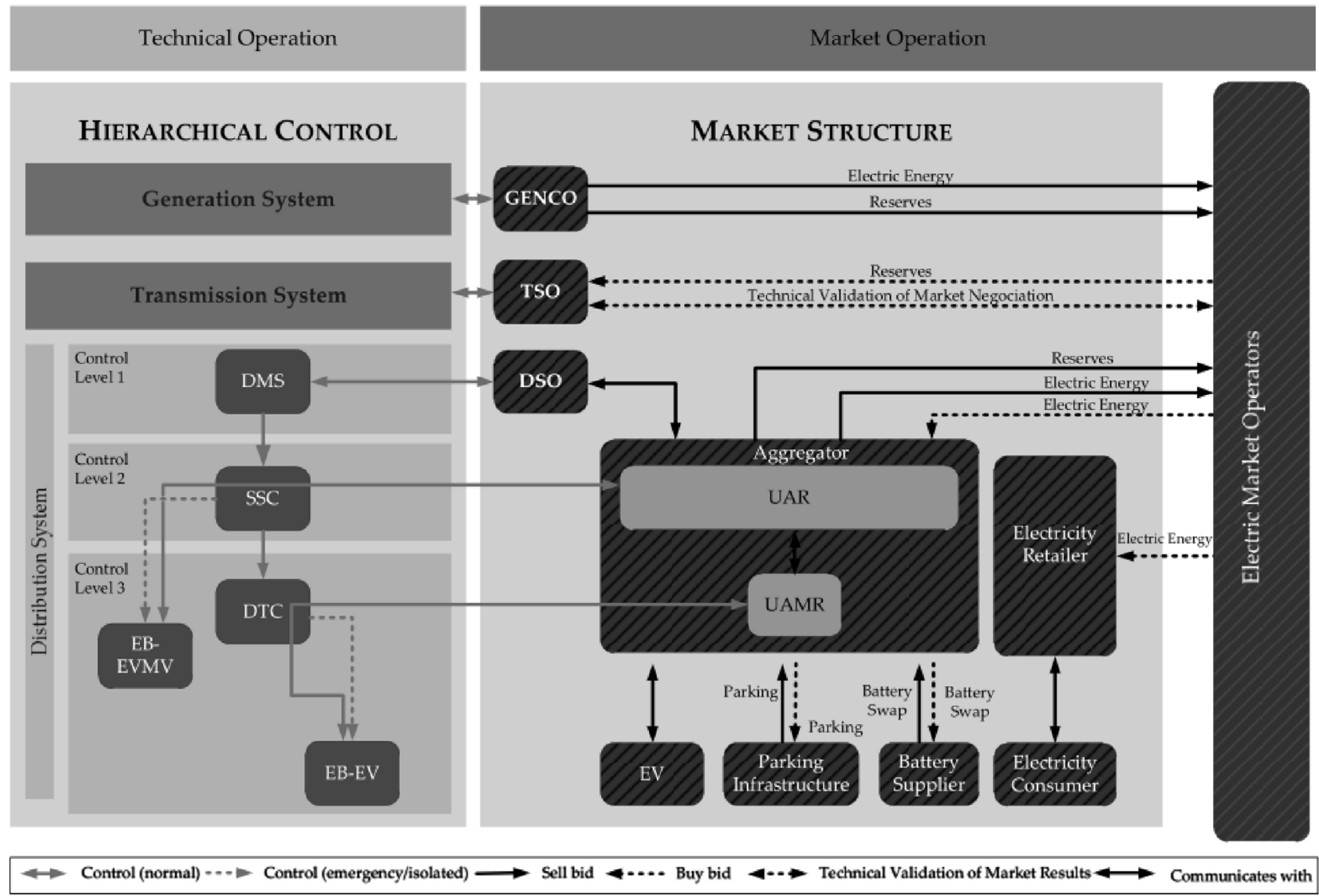

Fig. 2. REIVE technical and market operation architecture.

The third phase is ongoing and includes the integration of several advanced functionalities towards a complete SG vision. As an example, coordinated voltage control strategies (involving all the resources available in the distribution grid), forecasting algorithms for load, EV charging, distributed generation and microgeneration, novel state estimation techniques and remotely controlled bidirectional inverters for storage and $\mathrm{EV}$ management are foreseen to be implemented until 2016. Fig. 3 summarizes the functionalities developed for the new control layers, namely the DTC and the EB. The functionalities of the SSC are still under development. In the figure, HV stands for high voltage $(60 \mathrm{kV})$, MV for medium voltage ( $30 \mathrm{kV}$ or $15 \mathrm{kV}$ ) and LV for low voltage ( $400 \mathrm{~V}$ ).

At the MV level the SSC integrates coordinated voltage control strategies, distributed energy resources management and fault location and isolation. The voltage coordination strategies aim at minimizing renewable energy curtailment due to grid technical restrictions. After the identification of a violation of the voltage technical restrictions (either at the MV or LV grids), the resources owned by the DSO (on-load tap-changer transformers, capacitor banks and other reactive power compensation devices) and reactive power support services from distributed generators are exploited in order to solve the technical problem. If these resources are not enough, renewable generation curtailment is considered in a second step [8].

Within the defined architecture, fault location and isolation functionalities can also be improved based on the information collected by the SM, contributing to shorter restoration times and reducing the number of affected clients. This functionality has been initially integrated at the DMS outage management system in order to allow a faster identification of the fault location. However, with future distributed control strategies fault location and isolation is expected to be automated and integrated at the SSC level, being less dependent on the human intervention.

The DTC integrates management functionalities for the LV network operation, aiming at correcting voltage or congestions
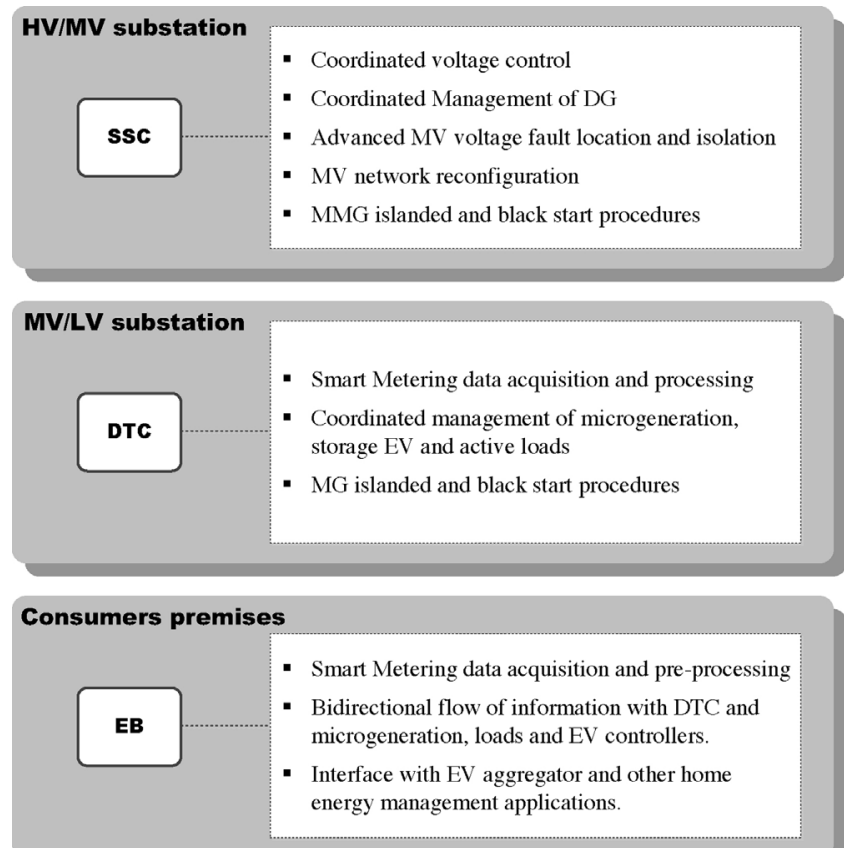

Fig. 3. Advanced decentralized functionalities for smart distribution networks 
problems related to microgeneration and EV integration. Realtime management functionalities will be supported by forecasting algorithms for load, EV charging and microgeneration such as photovoltaic (PV) panels and wind turbines, which can be centralized at the DMS or integrated in the SSC. Up to now, only solar power generation forecasting algorithms were developed. They are based on vector auto-regression theory, combining spatial-temporal data collected by EB and DTC to produce six-hour-ahead forecasts at residential and secondary substation levels [9]. Load and EV charging forecasting algorithms are still under development.

For self-healing purposes more advanced functionalities were considered to be integrated at the SSC and DTC, namely for islanded operation of MV and LV networks under the MMG and MG concepts [10]. Bottom-up restoration procedures were also considered to be conducted by integrating algorithms at the DTC and SSC [11]. The centralized functionalities housed at the SSC and DTC were complemented by local control strategies, which increase the flexibility of EV and microgeneration. The islanded operation of LV networks and restoration procedures have been validated both through simulation and experimentally in the laboratory facilities presented in Section 4.2. The management algorithms are complemented by local control strategies implemented at the EV and microgeneration grid coupling devices.

\subsubsection{EV integration control concepts}

Large scale deployment of EV will require new charging interface infrastructures, such as fast charging stations, public and domestic charging points and private charging stations. Unlike fast charging stations, all the other infrastructures will provide a slower charging, that can take up to $8 \mathrm{~h}$. Thus it is expected that EV are connected to the grid for large periods of time allowing the exploration of their storage capacity to enable a better usage of the network infrastructures [12].

For this reason, several possible charging schemes should be available in order to fit the specific needs of the EV owners. Four charging modes have been identified, namely: dumb charging, multiple price tariff, smart charging and vehicle-to-grid (V2G) mode [13]. In dumb charging, the EV behaves as any other appliance, which can be charged whenever needed. A multiple price tariff policy may be explored to incentivize a load shifting of EV charging to periods were the electricity price is lower, but the success of this passive method depends on the willingness of owners and associated incentives.

In smart charging specific control signals are exchanged to control the EV charging [14]. It envisions an active management system based on the system architecture represented in Fig. 2. In normal operating conditions, the EV charging will be managed and controlled exclusively by a commercial aggregator, whose main purpose is to cluster EV, according to the willingness of their owners, and explore business opportunities in electricity markets. The implementation of the smart charging strategy by an aggregator relies on the utilization of an optimization problem that defines which EV should charge at each time step to minimize the deviations between the energy profile derived from the negotiation in the day-ahead market and the energy effectively being consumed by EV [12]. To this end, the EV aggregator must be capable of exchanging set-points with the EB-VE related with rates of charge or requests for provision of ancillary services.

When the security of operation is compromised, the DSO can override the aggregator control and manage the EV charging directly. This approach allows the management of grid technical constraints, enabling congestion prevention and improving voltage control, while avoiding the need to invest largely in grid reinforcements [13]. In this case the V2G charging mode can be considered, allowing the injection of power into the grid. However, an economic incentive for EV owners is needed to compensate

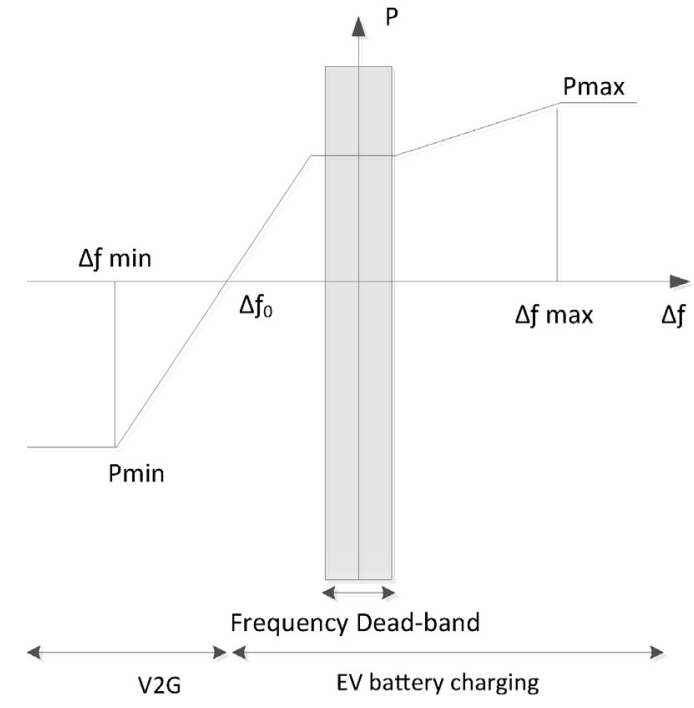

Fig. 4. EV active power-frequency droop control.

them for the potential degradation of batteries associated with the charge/discharge cycles and frequent shifts from injecting to absorbing modes.

The additional storage capacity of EV can be used to enhance the grid resilience, namely in isolated systems, by improving the frequency response and increasing the amount of renewable-based microgeneration that can be safely integrated in the system [15]. The EV participation in frequency regulation schemes followed two approaches: one for interconnected systems and the second for islanded systems, such as the MG.

When the system faces severe disturbances at the transmission level, the EV can participate in secondary frequency control by providing secondary reserve through its aggregated integration within the automatic generation control (AGC) functionality [16]. In this case the participation of $\mathrm{EV}$ is ensured by the commercial aggregator which will be responsible for sending individual control signals to the vehicles' controllers according to an aggregated reference received from the AGC.

In islanded systems, such as the MG or real islands, the system resources for performing frequency regulation are usually reduced. Therefore, integrating flexible resources to ensure the MG stability are important. In this case the EV participation in primary frequency control was considered based on the active power-frequency $(P-f)$ characteristics shown in Fig. 4. The power output changes with the grid frequency, reducing the imbalance between generation and load. A dead-band is set to avoid reacting to small frequency deviations. For large frequency disturbances, the V2G mode can also be enabled allowing the charger to change its power flow direction.

Besides participating in frequency regulation strategies, the EV load flexibility and storage capacity may also be useful for voltage control purposes during normal (interconnected) operation. Similarly to frequency regulation scheme, an active power-voltage $(P-V)$ droop characteristic was tested, allowing the EV to increase its charging rate when the terminal voltage increases outside admissible values. For low voltages, the EV decreases its charging rate or reverses its power flow. A $P-V$ droop was used since LV distribution networks have in general a low $X / R$ ratio, making voltage highly dependent of the active power injected.

Frequency and voltage droop parameters will depend on the EV charger characteristics and the willingness of EV owners to participate in such services. Both $P-f$ and $P-V$ droop characteristics are integrated as external control loops of the EV charger, so that the control will only depend on local measurements allowing a fast 


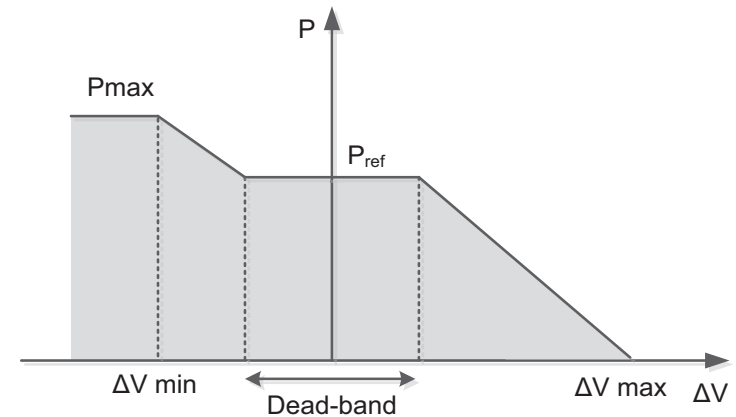

Fig. 5. Microgeneration active power-voltage droop control.

response to the system transients. However, in order to allow its coordination with higher control layers (DTC, SSC and DMS), the droop control can be enabled or disabled by the DTC.

\subsubsection{Microgeneration control concepts}

The traditional low $\mathrm{X} / \mathrm{R}$ ratio of $\mathrm{LV}$ grids together with the reduced simultaneity between load and renewable generation, such as PV, may cause severe voltage rise problems. These might lead to overvoltage tripping of microgeneration, thus limiting the amount of renewable based generation that can be safely integrated in the distribution system without compromising power quality [17].

Local active power control strategies based on the local voltage measurement may avoid unnecessary curtailment of microgeneration units, since it will reflect the network load conditions. The droop based control method represented in Fig. 5 was proposed under project REIVE to determine the necessary power curtailment while mitigating the voltage rise at the unit's terminals [18]. When the voltage exceeds the pre-defined dead-band, the microgeneration output power is reduced to limit the voltage rise effect. On the contrary, if the microgeneration unit was being operated below its maximum capacity and the voltage drops below the dead-band, the unit can increase its power. The main disadvantage of this type of control strategy is that the units connected to the end of the feeder will have higher solicitation regarding units installed near the MV/LV substation.

The voltage control strategies can be applied to both PV and wind turbine generating systems. In both cases, decreasing active power output wastes renewable based energy. However, the EV voltage control strategy described earlier will contribute to reduce the renewable energy waste since it will increase its charging power compensating the excess power generation.

\section{Advances in SG simulation platform and tools}

The development of new technical and operation architectures integrating new SG functionalities and control concepts required the development of a computational suite, composed of both network analysis and communication simulation tools, in order to validate the effectiveness of the algorithms and technologies.

\subsection{Network analysis platform}

The main objective of the analysis tools that were developed was to study the technical impacts of the large scale integration of microgeneration and EV in the Portuguese electric power system. The simulation tools were initially developed under InovGrid project and then extended to include REIVE concepts. The main objectives of the simulation tools are:
- Steady state simulation tools - quantify the impact of microgeneration and EV integration in the Portuguese distribution system, namely the change in demand patterns, changes in the grids' voltage profiles, line overloading and energy losses.

- Dynamic simulation tools - test the effectiveness of EV for primary and secondary frequency regulation. Primary frequency regulation is based on the $P-f$ droop strategy previously described and it is intended for islanded systems (either MG, MMG or real islands). Participation of EV on secondary frequency regulation is envisioned for the transmission system through a new AGC model, as previously discussed.

The steady-state simulation tool is an important tool for utilities today by identifying the networks bottlenecks and technical problems. This tool consists in an algorithm implemented in Python programming language [19] that characterizes, in half an hour time steps, the network under study regarding load, EV consumption and power produced by microgeneration units and uses PSS/E commercial software to run the power flow studies.

In order to estimate EV consumption, the tool simulates their movement and battery state-of-charge in half an hour time steps. A stochastic model based on a Monte Carlo method is used to characterize the EV regarding different drivers' behaviours, charging strategies, battery capacities, charging rates and energy consumptions per distance travelled $(\mathrm{kWh} / \mathrm{km})$ [20]. The simulations can be conducted for different time periods, namely an hour, day or week.

Fig. 6 shows the number of EV that are expected to be connected to a MV network, during a day, according to the adopted charging strategy. Their movement pattern will have a direct impact on the networks load diagram.

Fig. 7 shows the consumption pattern in a LV network considering different EV charging strategies. In this scenario approximately 63 plugged-in EV were considered. As shown, adopting a dumb charging strategy will increase the peak power ca. $62 \mathrm{~kW}$, since EV are likely to be charged at the end of the day, while adopting a multiple tariff scheme results in a new peak at 22:00 h, when the period with a lower tariff begins. However, when adopting a smart charging strategy the EV charging occurs preferentially on the valley hours, contributing to keep the peak load almost unchanged.

Regarding technical impacts, Fig. 8 provides a comparison of branches loading in the peak hour of the scenarios without and with $14 \mathrm{EV}$. Results were obtained for a LV grid with a $400 \mathrm{kVA} \mathrm{MV} / \mathrm{LV}$ transformer. In this case the maximum branch loading detected increased $45 \%$ with the dumb charging, $56 \%$ with the multiple price tariff and $11 \%$ with the smart charging. Grading between light blue and red stand for increasing values of lines loading (from 0 to $100 \%$ ).

Regarding the contribution of the microgeneration units, Fig. 9 shows the impact of three integration scenarios in the load diagram of a $630 \mathrm{kVA} \mathrm{MV/LV} \mathrm{secondary} \mathrm{substation} \mathrm{by} \mathrm{2030:} \mathrm{scenario}$ (1) business as usual; scenario (2) $250 \mathrm{MW}$ of microgeneration installed in Portugal ( $10 \mathrm{~kW}$ in the LV network under analysis); and scenario (3) $2000 \mathrm{MW}$ of microgeneration installed in Portugal ( $80 \mathrm{~kW}$ in this specific LV network). Since the majority of microgeneration units were assumed to be PV, during the hours with greater sunlight exposure there is only a small reduction in the peak power.

\subsection{Communications simulation platform}

Within the SG concept, communications represent the support infrastructure to enable the necessary information exchange to accommodate new services and functionalities with different requirements. The importance of a communications infrastructure was emphasized in both Portuguese SG initiatives described earlier.

Within the InovGrid project several communication technologies were identified to support the communications segments 


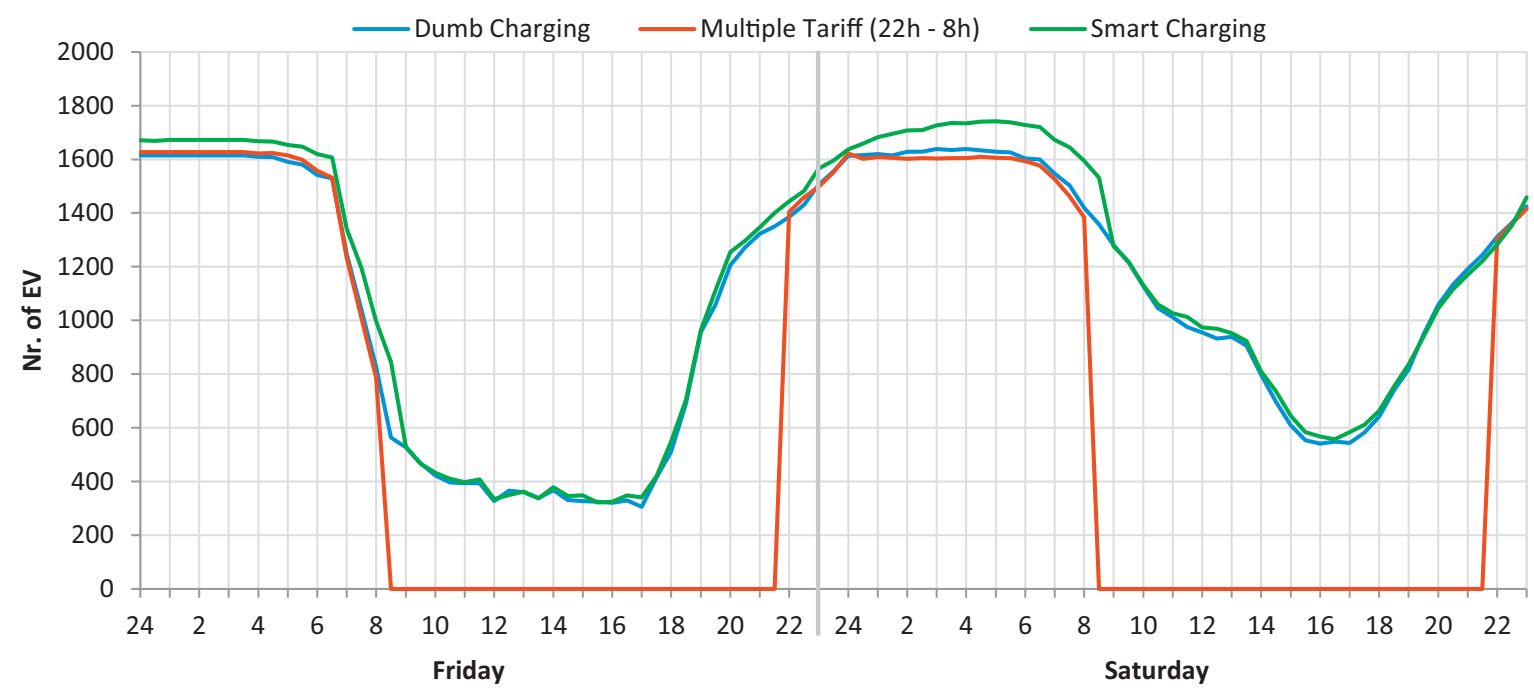

Fig. 6. EV availability: number of EV charging according to charging strategies adopted.

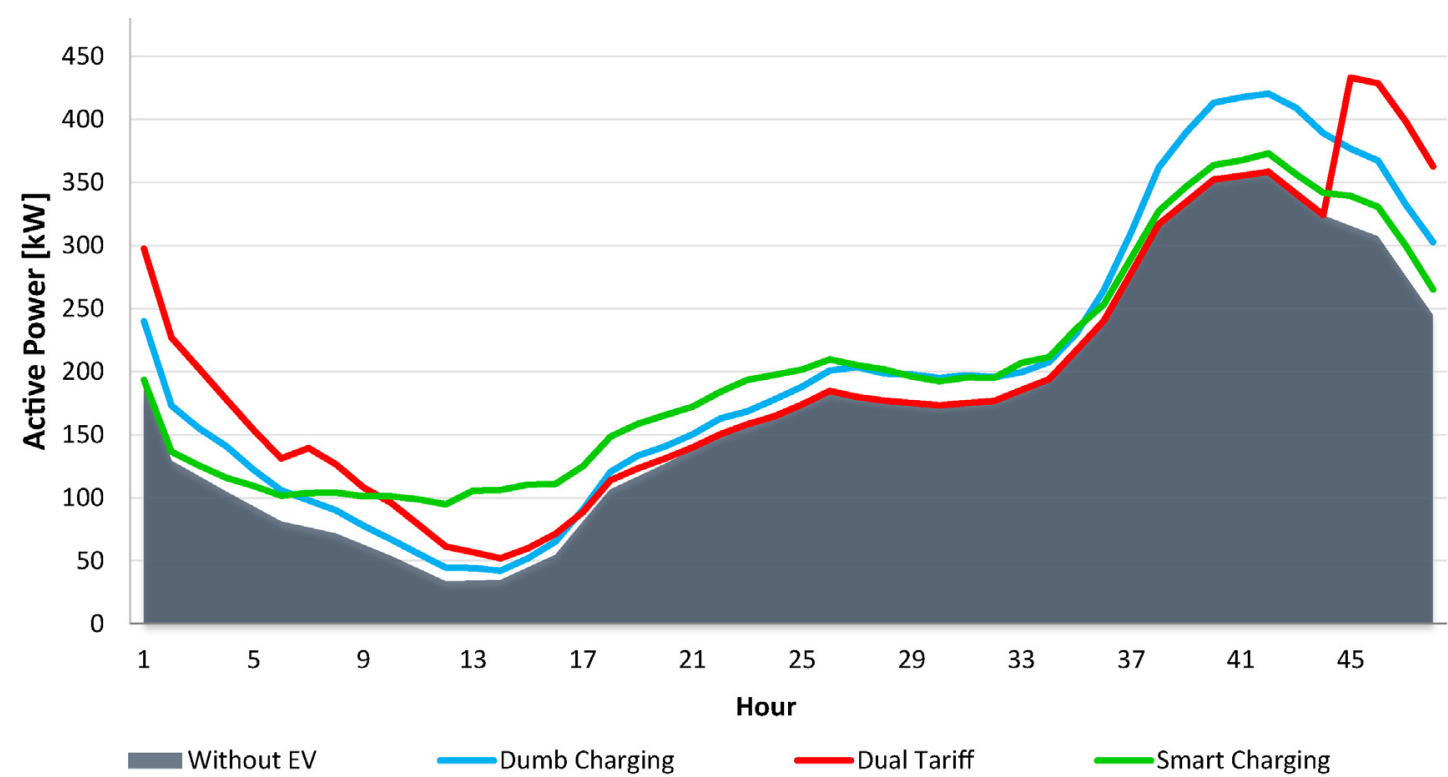

Fig. 7. Load diagram at the MV/LV substation adopting different EV charging strategies.

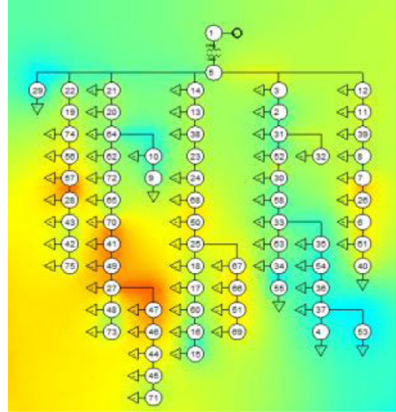

a) Base Case

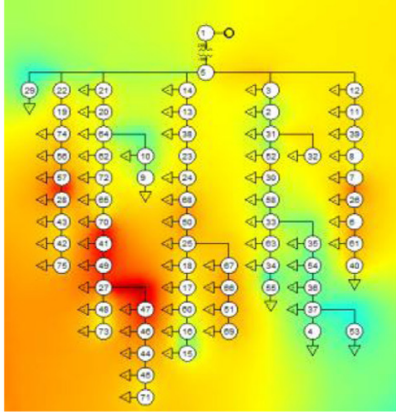

b) Dumb Charging

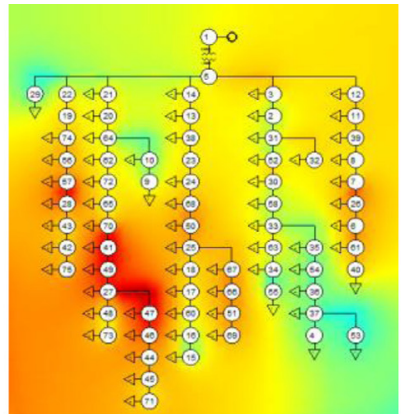

c) Multiple Tariff

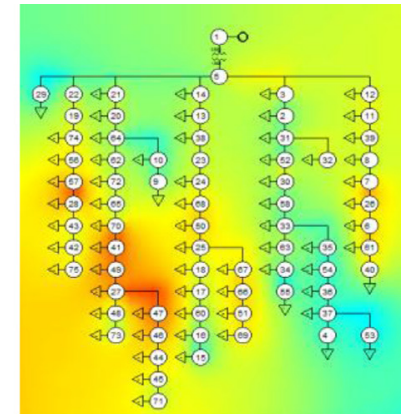

d) Smart Charging

Fig. 8. Impact of EV charging strategies in lines loading.

associated with the distribution grid. More specifically the impact of uncertainties associated with the communications systems was evaluated using a probabilistic approach to emulate delay variation and losses of information [21].
In REIVE a wireless mesh network implementation was performed in a simulation environment, using a discrete-event network simulator, ns-3 [22], and in a real implementation associated with the smart grids and electric vehicles laboratory, which 


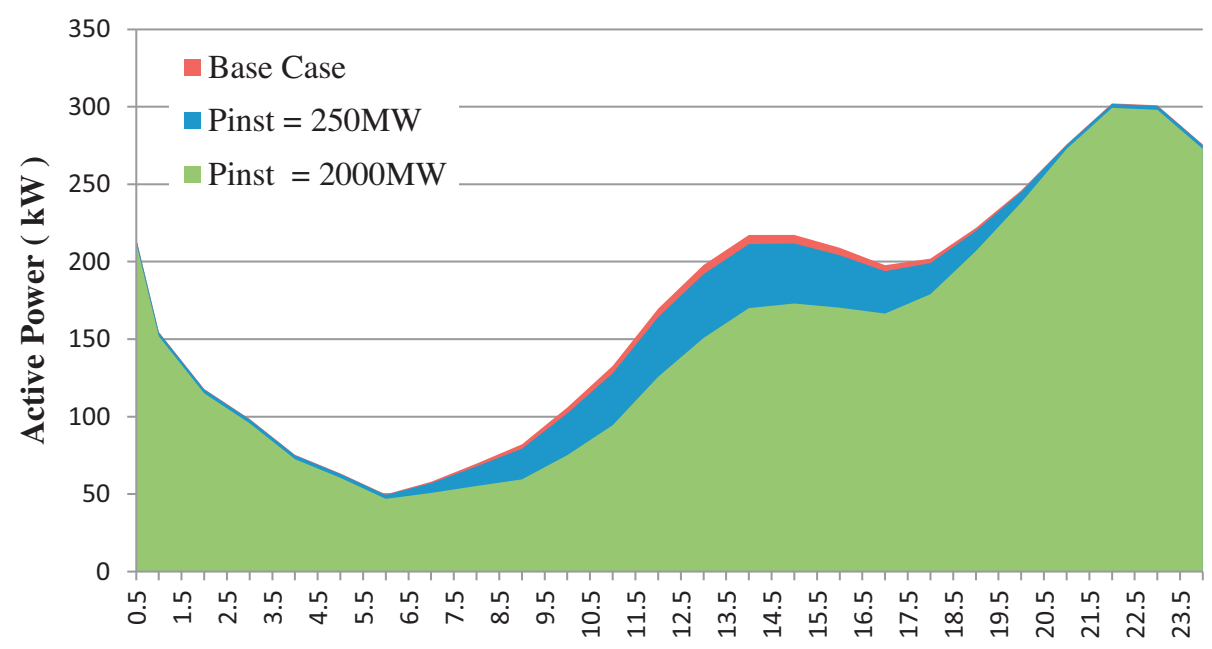

Time ( h )

Fig. 9. Load diagram at the MV/LV substation considering two integration scenarios of microgeneration for 2030.

is detailed later in this paper. Fig. 10 shows an aerial view of the deployed wireless mesh network that interconnects a substation controller and a SM.

A scheduling algorithm, based on a master-slave approach, was also introduced and further developed to meet the stringent requirement found in control applications related to the SG concept [23].

\section{Actual implementations}

The more relevant SG implementation projects in the Portuguese distribution network are the InovGrid and REIVE projects. In the former the basis for different pilot implementations of SG initiatives were established, whereas in the latter a laboratorial infrastructure was defined and implemented to allow the test and evaluation of SG monitoring and control strategies.

\subsection{InovCity}

One of the major achievements accomplished in the InovGrid project was the real implementation of a SG infrastructure in the
Portuguese municipality of Évora, which was designated as InovCity. It has 54,000 inhabitants and totals $1307 \mathrm{~km}^{2}$ of urban and rural area, thus comprising an adequate size and network diversity to support the field evaluation of a SG solution. The electric infrastructure spans over the entire municipality, reaching around $32,000 \mathrm{LV}$ customers with an annual consumption of ca. $270 \mathrm{GWh}$. Additionally, there are $140 \mathrm{MV}$ customers with an annual consumption of $110 \mathrm{GWh}$. Industrial activities account for $57 \%$ of electricity use, services for $34 \%$ and agriculture and other activities for $9 \%$.

Several municipal entities were involved in the InovCity, such as the City Hall and other relevant commercial customers (Fig. 11).

One of the main objectives in InovCity was to promote the engagement of customers in energy efficiency programmes, through the change of energy usage behaviours. This was achieved and the smart metering infrastructure played a central role in making customers aware of their expenditures. They had the possibility to permanently monitor their energy consumption and receive generic energy efficiency advices from the DSO. The InovCity Store also played a very important role in customer awareness, since it gave the required visibility to the project.

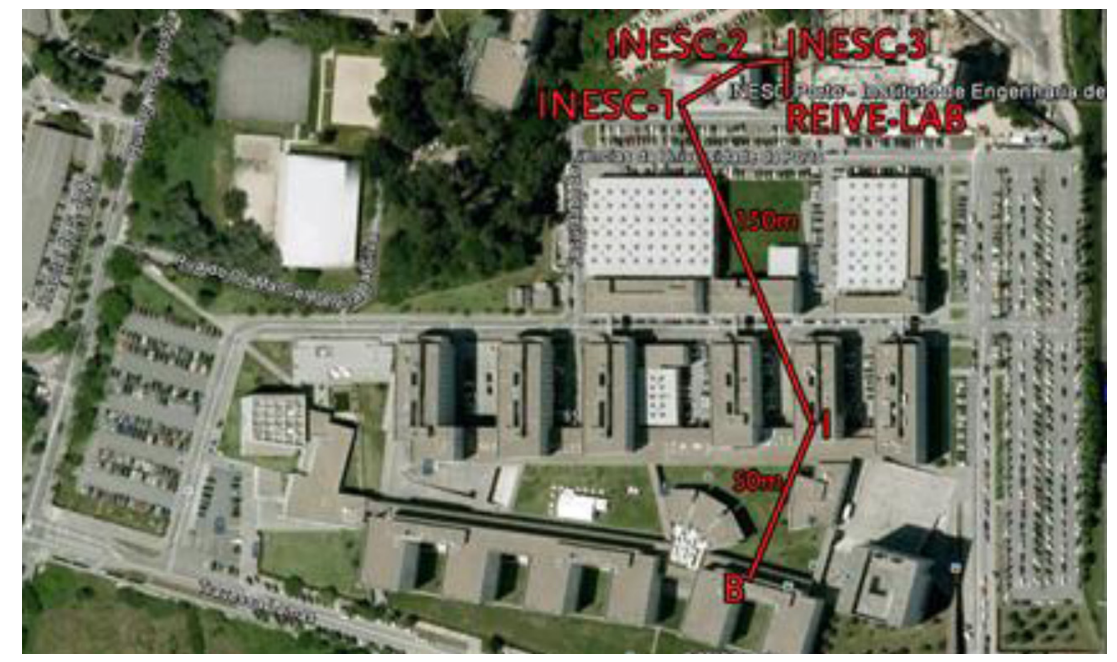

Fig. 10. Aerial view of installed WMN nodes. 


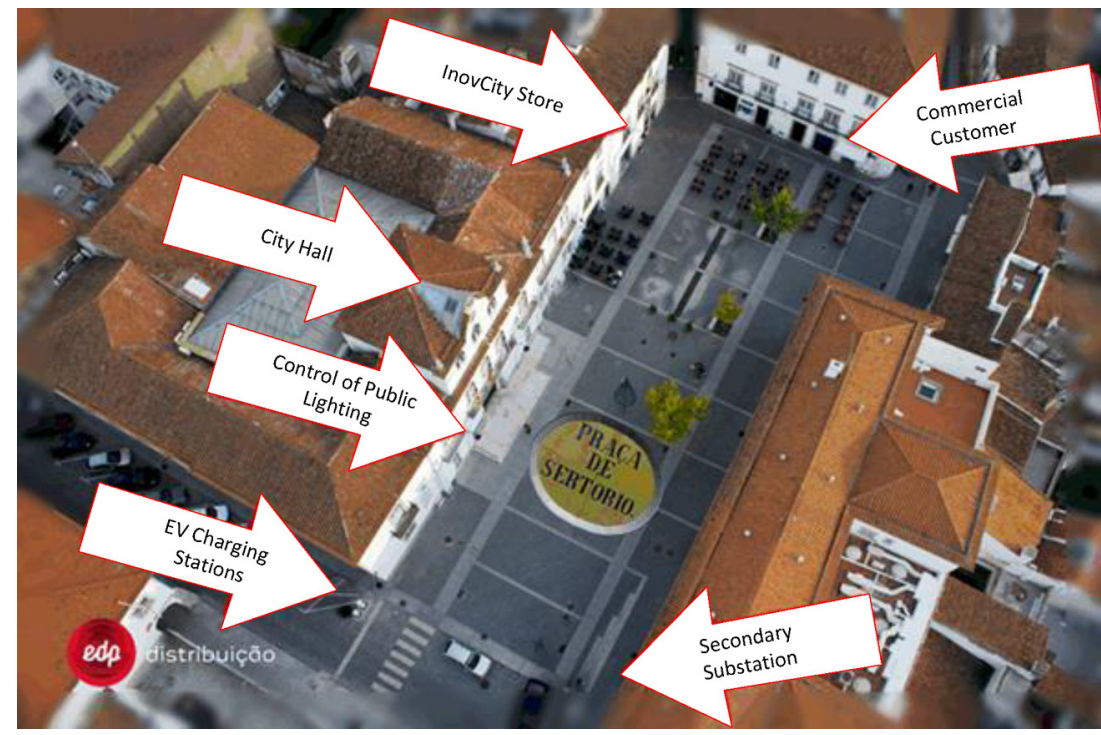

Fig. 11. InovCity management entities.

\subsubsection{Infrastructure and management architectures}

As shown in Fig. 12, the technical architecture developed for the InovGrid project was implemented in InovCity. The equipment developed by the InovGrid industrial partners, namely the EB and the DTC, were installed in all LV consumers and in all MV/LV substations, respectively. The commercial equipment integrates the functionalities specified in InovGrid project. The EB provides real time readings on active power and voltage and offers several remote services (connect/disconnect, contracted power modification, tariff setup, tampering alarms, etc.). The DTC acts as a data concentrator for the EB data, monitors the voltage per phase and provides other automation functionalities, such as active and reactive power monitoring and local sensors, both at the DTC and EB level. MV switching is also possible, but only at the DTC level. The communication between the EB, DTC and central systems is based on PLC and GPRS.

Besides testing its smart metering infrastructure, InovCity also focused on the consumers' engagement in the operation of the system. The objective was to understand the impact of customers' awareness in their consumption patterns. For that, EDP Distribuição provided a set of in-home displays to a test group, providing realtime information of their power consumption. As shown in Fig. 13, home area network was based on ZigBee and Wi-Fi. ZigBee was used in the communication between the displays and the EB, while Wi-Fi allowed sending consumption alerts by 20 public EV charging stations were also deployed in Évora, as well as efficient public lighting systems, based on LED luminaries with automatic dimming and remote control from the DTC (Fig. 11).

\subsubsection{Main outcomes of InovCity project}

The business cases for InovGrid and InovCity projects are based on a set of economic, ecological and social benefits for different stakeholders, such as the DSO, electricity users, energy services companies, electricity retailers, distributed generation promoters and electric vehicle owners. Fig. 14 summarizes those benefits and

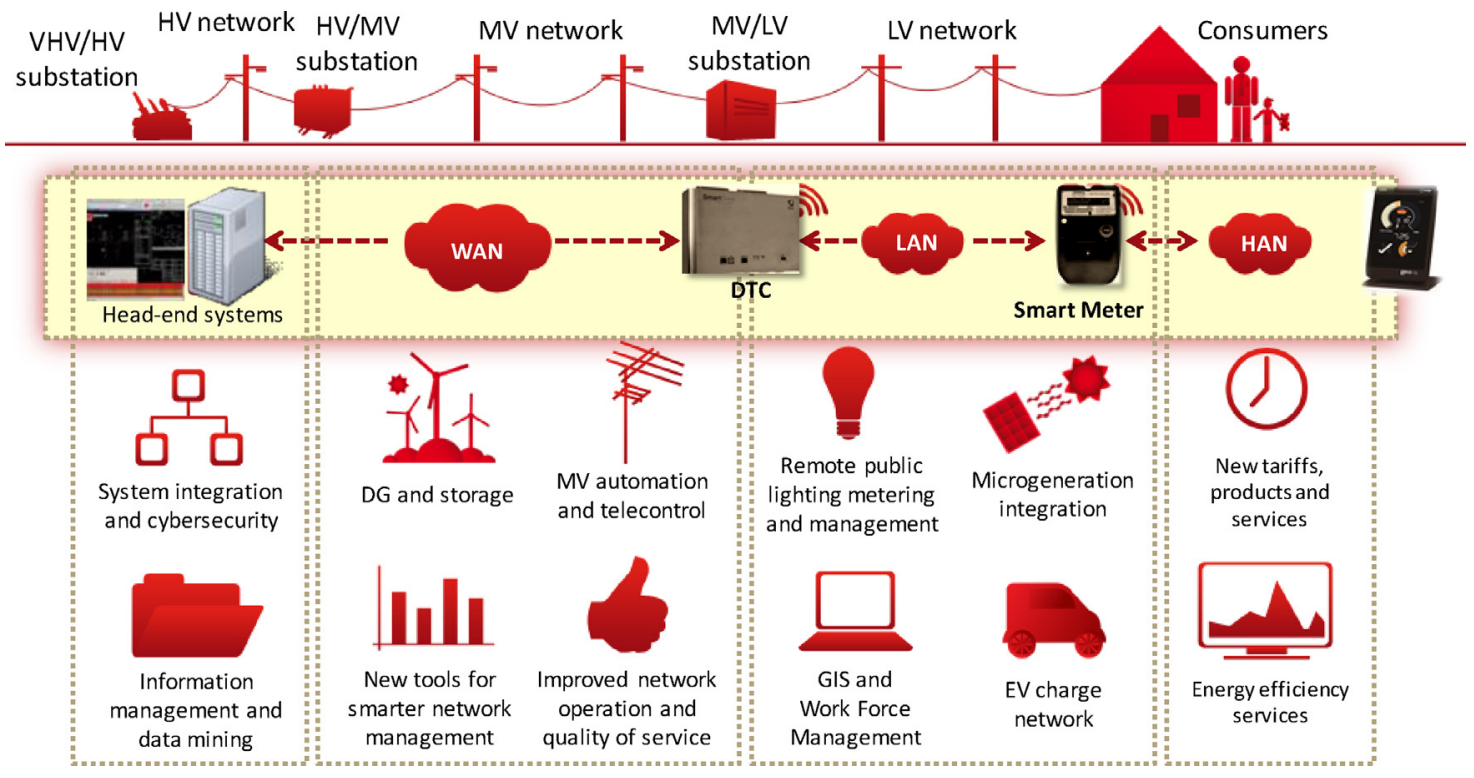

Fig. 12. InovCity architecture. 


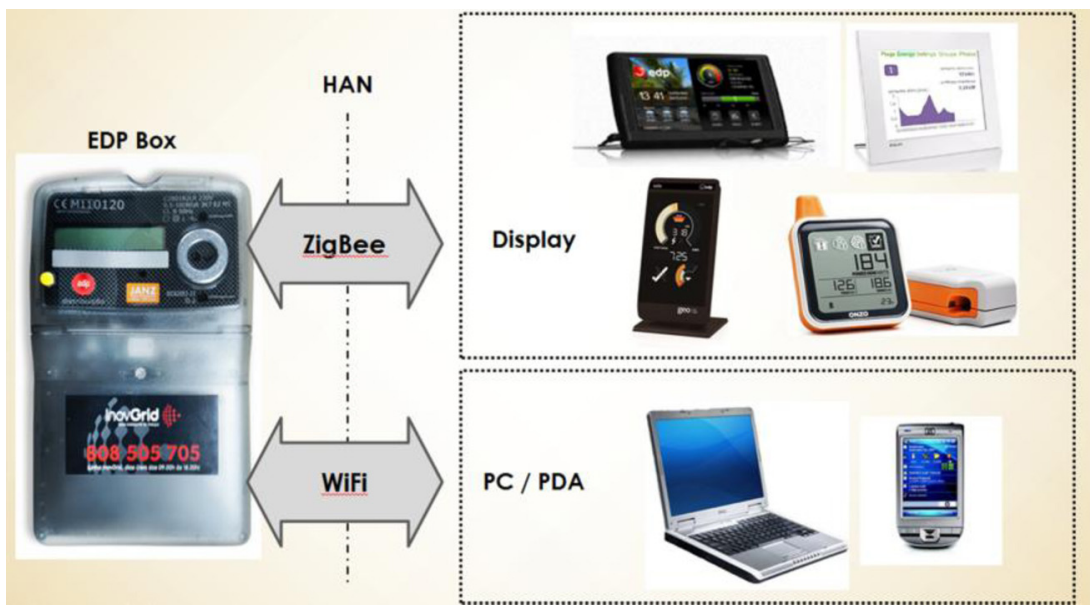

Fig. 13. Customer in-home energy monitoring system.

identifies the key performance indicators adopted to evaluate the project performance.

The achieved results, in terms of energy efficiency, were encouraging. By monitoring the electricity consumption of customers in Évora and comparing it to a control group in a nearby municipality, with similar socioeconomic and climatic conditions, it was possible to evaluate the gain of having a smart metering system deployed. Results were evaluated by gathering metering data over an initial year and their persistence was analyzed in subsequent years, as depicted in Fig. 15.

In the first year, a 3.9\% reduction in consumption was observed in comparison with the control group. In the second year, this

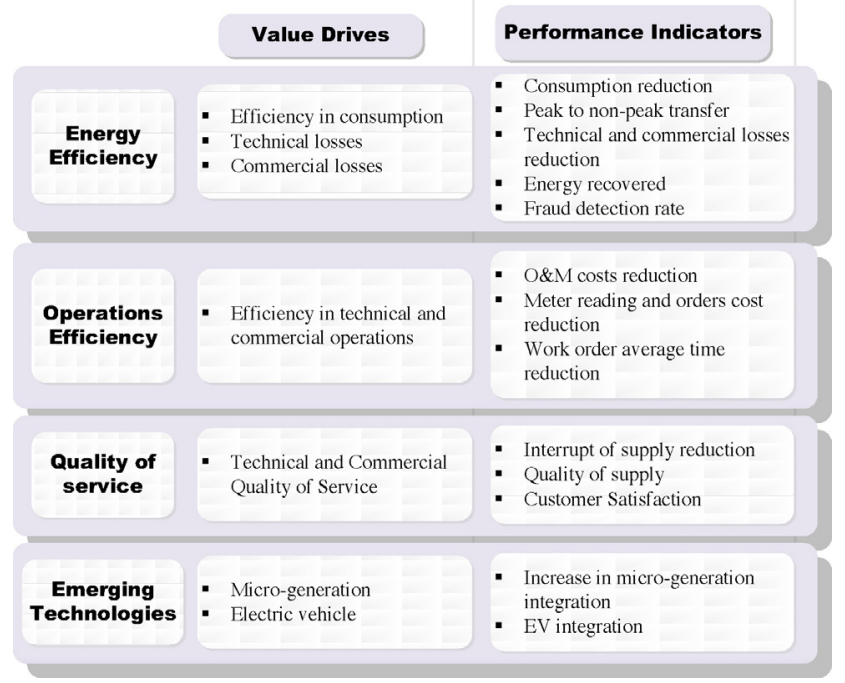

Fig. 14. InovGrid and InovCity benefits and key performance indicators.

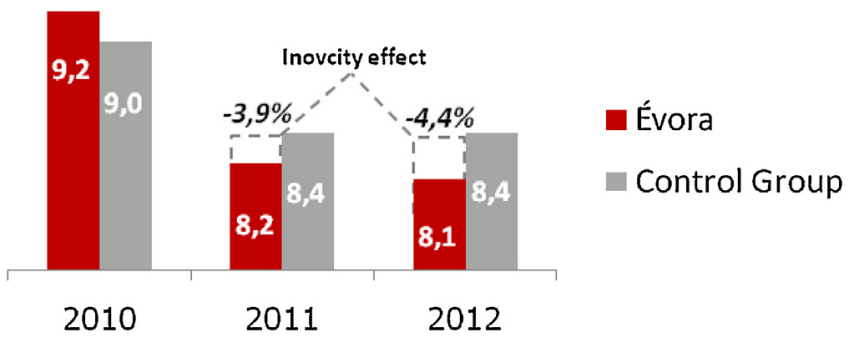

Fig. 15. InovCity consumption results. difference increased to $4.4 \%$. A $6.6 \%$ reduction in the consumption of the clients with access to in-home energy monitoring systems was reported when compared to the results observed in 2010.

From an operational point of view, the InovCity implementation allowed $97 \%$ of the invoicing being based on real consumptions rather than estimates. A reduction of $5-10 \%$ of outage time was also reported. Regarding microgeneration, the number of installations increased 66\% in 2012 when compared to 2010 (from 339 to 563 units).

Results achieved in the project led EDP Distribuição to replicate the concept to other locations to consolidate knowledge and test technologies in different contexts. Currently, the following test sites are under development: Marinha Grande (quality of service improvement), São João da Madeira (strong urban and industrial concentration), Faro's Islands (isolated networks), Alcochete (new technologies test site), Lamego (rural network) and Guimarães (urban city) will be the new test sites.

\subsection{Smart Grids and Electric Vehicle Laboratory}

The Smart Grids and Electric Vehicle Laboratory is an instrumental result from REIVE project, which was implemented as a modular and flexible infrastructure capable of accommodating current and future SG concepts. The laboratory represents a near-real experimental tool to test and evaluate individually or in an integrated fashion, new concepts such as advanced control algorithms, decision making strategies, communications solutions and information exchange schemes.

The laboratory has also been used to make a pre-validation of some of the functionalities to be implemented in InovCity. Voltage and frequency regulation strategies, algorithms to coordinate the operation of microgeneration, storage and EV and remotely controlled bidirectional inverters for EV charging were already tested in the laboratory. The isolation of the experimental test system from the main grid was also tested, to explore MG islanded operation scenarios. Currently, advanced demand response strategies and state estimation techniques are under test.

\subsubsection{Infrastructure and control architecture}

The electric infrastructure of the laboratory is composed of several devices, such as: commercial grid tied and grid forming inverters, solar panels, a micro-wind turbine emulator, batteries (lead-acid and Li-ion), a slow charging station and a set of LV cable emulators and resistive load banks. A four-quadrant back-to-back inverter is also available, which can be remotely controlled, emulating a microsource or a controllable load. Control parameters can 


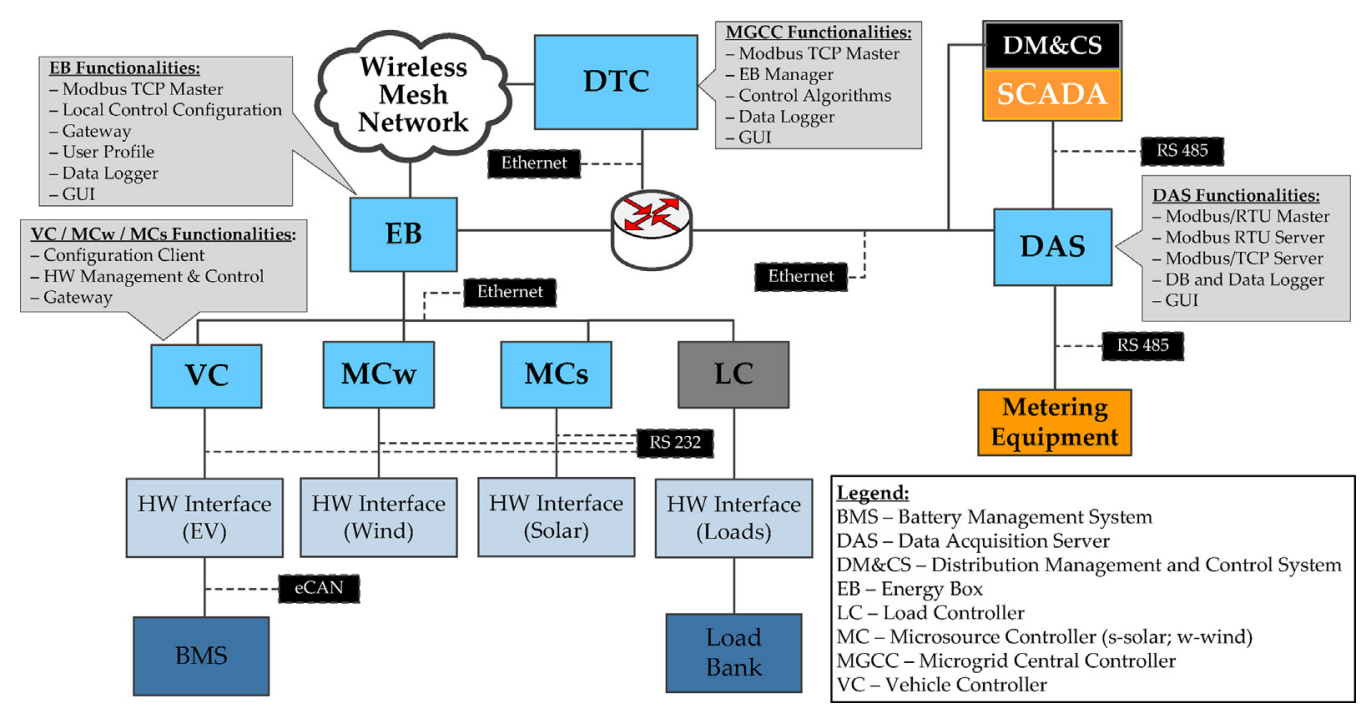

Fig. 16. Smart Grids and Electric Vehicle Laboratory architecture.

be configured locally or remotely to allow their operation under different conditions.

The electric network available in the laboratory infrastructure includes the necessary protection, automation devices and measurement systems that are integrated in a central SCADA system. The electric panel allows a flexible composition of two different LV MG with different equipment combinations. The flexible structure of the electric panel enables the connection/disconnection of devices and the isolation of the experimental test system from the main grid, to explore MG islanded operation scenarios.

The distribution network operation architecture developed under project REIVE was implemented in the laboratory and integrated with the existing SCADA system. As shown in Fig. 16, two control levels were implemented: namely the DTC and the EB. At the lower control layer, the EB has bidirectional communication capabilities to ensure the exchange of control signals and other information between the DTC and the EV, microgeneration and load controllers. The information available from the local controllers can be sent to the DTC and used as inputs to the MG high level management and control functionalities. The information received from the EB includes power generation, load and EV charging power and other information related to the EV battery state (state of charge, state of health, alarms, etc.).

\subsubsection{Communications infrastructure}

A communications solution was designed to interconnect the laboratory backbone SCADA system, used in this scope for supervision and automation purposes, with other devices that compose the Smart Grids and Electric Vehicle Laboratory. Fig. 16 presented

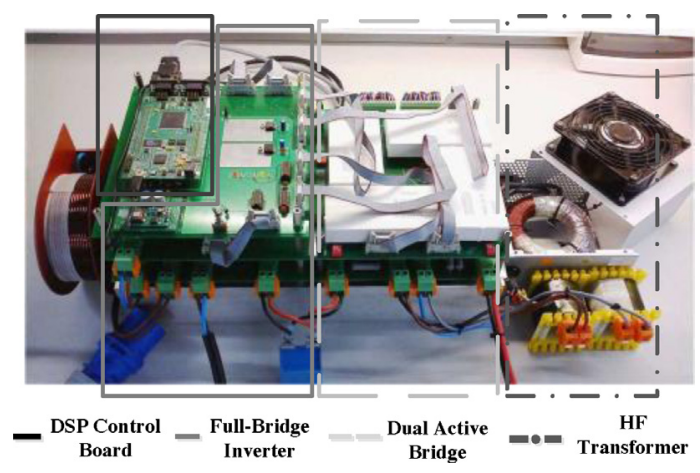

Fig. 17. EV bi-directional charger prototype. earlier is also a representation of the communications architecture that supports the laboratory, with the links between the control structure, the SCADA system and the end applications through $\mathrm{EB}$, either for general distribution customers or specifically for EV charging applications. All the communications links have associated a medium behaviour controller (MBC) which is a software entity responsible for the emulation of the communication medium according to propagation characteristics, bandwidth, delays and losses, which are variables typically associated with the performance of communications systems.

A full duplex Ethernet based solution was deployed as the basic communications infrastructure designed to emulate the communications found in the distribution and end customer segments of SG. This cabled solution represents virtually an unlimited bandwidth and noiseless data exchange medium over which some control will be effectively performed by means of a MBC. Hence, its usage allows the emulation of different technologies and scenarios of application by introducing controlled packet loss schemes, delay variation, jitter, simulation of loss of connectivity and other phenomena associated with real communications channels and networks. The implementation of the MBC is performed through software modules, which are responsible for the management and control of the information flows associated with communications interfaces of the different nodes participating in the laboratory network. These modules are responsible for the interaction with the communications interface drivers and operating system kernel configurations to set different communication scenarios.

The communication links and the respective technology are represented in Fig. 16 between all the different participating entities of the laboratory. For simplicity only unique entities are represented, but it is possible to establish configurations with multiple nodes.

A wireless mesh network, as mentioned earlier and depicted in Fig. 10, is used as an alternative to the Ethernet cabled solution. This network extends over the faculty campus and it implements a multi-hop communications infrastructure that is able to convey control data over a communications network deployed in a realworld environment. The laboratory communicating nodes are thus able to select over which network the data should be exchanged. This is accomplished by means of selecting the respective communication interface.

\subsubsection{Microgeneration and EV prototypes}

One of the important contributions of REIVE project was the development of custom tailored prototypes, namely a solar and 


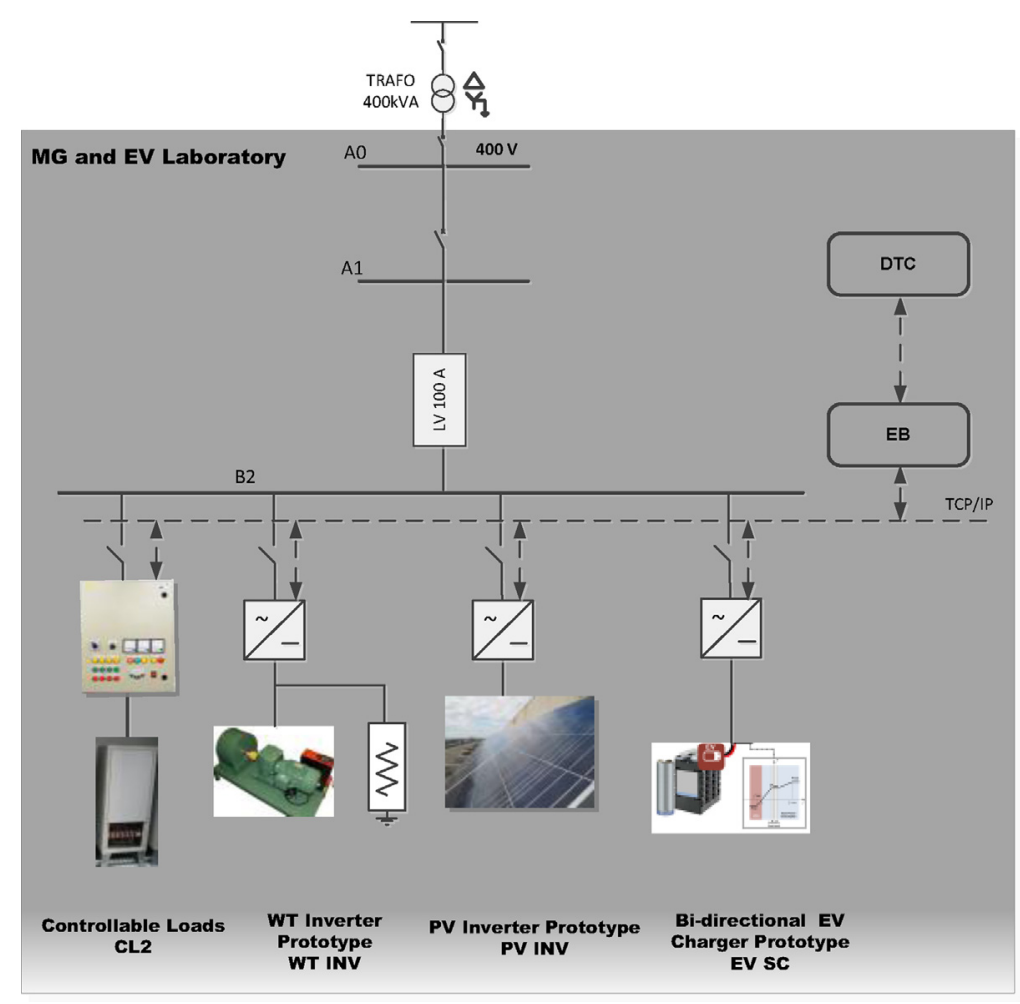

Fig. 18. Experimental test system and control architecture.

wind grid-coupling inverters and a bidirectional EV charger. The prototypes incorporate the droop control methods based on voltage and frequency droop characteristics that were described earlier.

The microgeneration inverter prototypes are equipped with power electronic converters composed of half-bridge assemblies, including IGBT switches and hybrid gate drivers, as well as passive components like protection devices, voltage and current sensors and control hardware. The EV bidirectional charger prototype allows charging the associated batteries and injecting power in the grid if required. The charger, illustrated in Fig. 17, comprises two stages with independent control schemes: a grid tied full-bridge inverter that controls the power flow between the DC bus and the grid and a dual active bridge that regulates the current flowing from/to the batteries and assures the galvanic isolation between the grid and the battery pack. The full-bridge inverter regulates the DC bus voltage in order to ensure adequate supply to the dual active bridge input stage. The inverter is controlled with a $P-Q$ strategy within a limit of $\pm 3680 \mathrm{~W}$, using a proportional-integrative controller implemented in a synchronous reference frame [24].

\subsubsection{Experimental capabilities}

The laboratory was designed to enable the individual and integrated testing of new technological solutions and control algorithms to be housed at the different SG hierarchical layers,
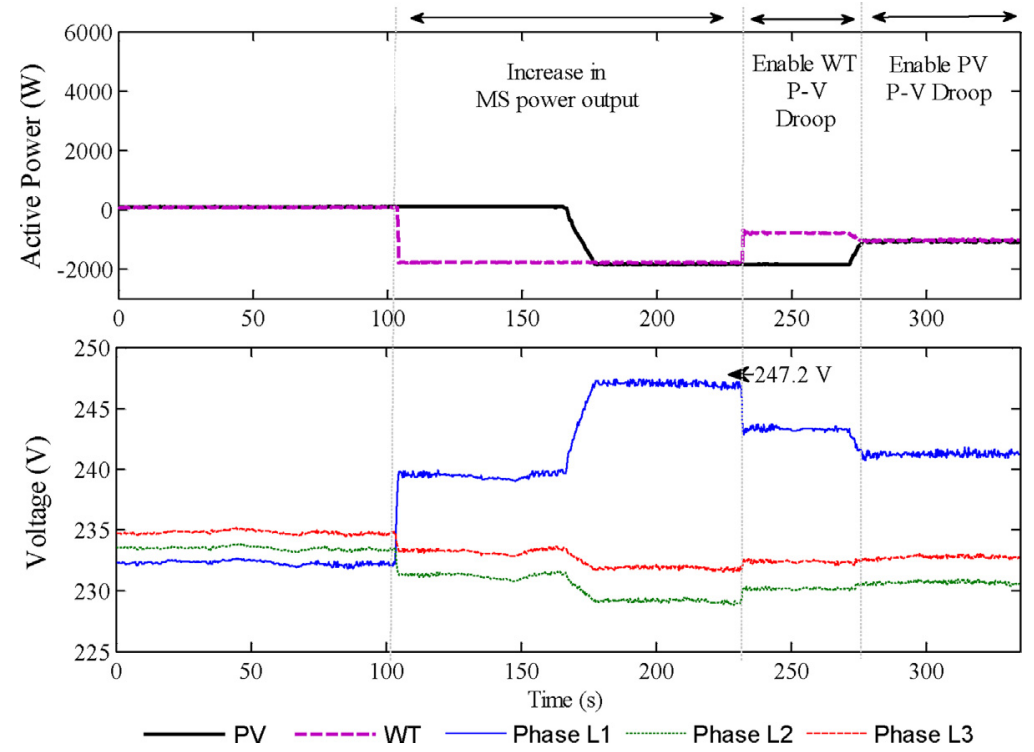

Fig. 19. Microgeneration voltage control experiment. 

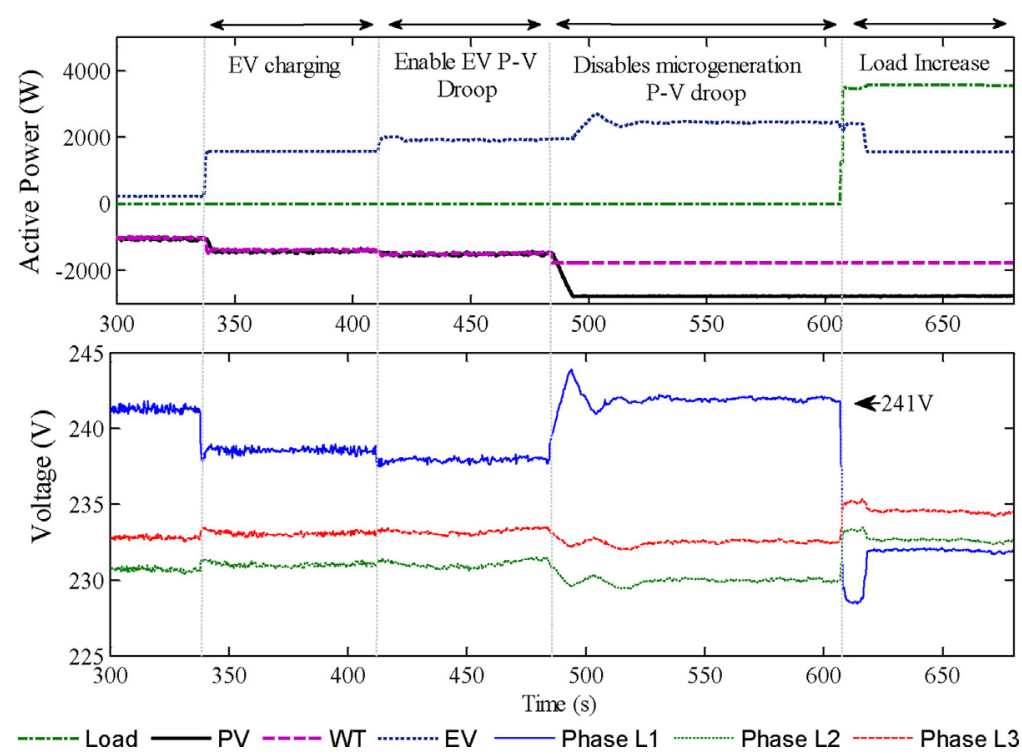

Fig. 20. EV voltage control experiment.

communications architectures, technologies and protocols. In this sense, the main research objectives of the REIVE laboratory are:

- Experimental validation of MG concept as the base active cell for SG, namely voltage and frequency regulation strategies.

- Development and test of software modules for pre-prototypes of SG key controllers (such as DTC, SSC, etc.).

- Development of algorithms to coordinate the operation of microgeneration, storage and EV (smart charging and V2G).

- Support and provide data for solar, wind and load forecasting methods.

- Development of new hardware and software prototypes for monitoring and control smart home appliances.

In addition to the research objectives, the laboratory infrastructure provides a flexible testing platform for the development of new SG related products. The laboratory is expected to actively support national and international standardization activities in different domains, according to the laboratory developments obtained in the project and promote technology transfer to the industry.

\subsubsection{Main achievements}

The work developed so far focused on the development and test of new inverter control methods for the power electronic interfaces of microgeneration, EV and storage. One of the main concerns regarding microgeneration integration in distribution networks is related to the changes in the voltage profile of LV networks, when considering operation scenarios with a large integration of renewable based microgeneration.

Figs. 19 and 20 show the results obtained in the lab for the test system in Fig. 18, considering an off peak load scenario with high integration of microgeneration. In this case the voltage control functionalities are remotely enabled by the DTC.

At $t=104 \mathrm{~s}$, the active power production of the wind turbine increases, leading to a significant increase in the phase voltage (from 231 to $240 \mathrm{~V}$ ). At $t=167 \mathrm{~s}$ the active power production of the PV panel also increases causing a voltage increase to $247.2 \mathrm{~V}$.

Voltage in the EB node is being monitored by the DTC through the information exchanged periodically between the two controllers. Since voltage is close to admissible limits ( $\pm 10 \%$ Un) the DTC activates the droop control functionality. In this case, for demonstration purposes the wind turbine control will be activated first at $t=230 \mathrm{~s}$ followed by the activation of the PV control at $t=270 \mathrm{~s}$. When the wind turbine voltage control is activated, it is possible to observe an immediate reduction of the power injected and consequently a reduction in the phase voltage. The same happens when the PV panel droop control functionality is activated. In this case, since there is more than one unit participating in voltage control the microgeneration units share the active power reduction.

When the microgeneration units controlled through the voltage droop functionality reduce their power output, the efficiency is reduced either by changing the operating point or by dissipating the excess power in the wind turbine dump load. However, we could improve the systems efficiency if the EV could charge their batteries.

Fig. 20 shows the effect of EV control in the grid voltage. At $t=337 \mathrm{~s}$, the EV starts charging, decreasing nodes voltage and allowing the microgeneration units to increase their power output from $1 \mathrm{~kW}$ to $1.35 \mathrm{~kW}$ approximately. At $t=410 \mathrm{~s}$ the EV controller receives a control signal from the DTC to activate voltage control. Due to the network voltage the EV will slightly increase their charging power from $1.5 \mathrm{~kW}$ to $2 \mathrm{~kW}$, allowing the increase of the microgeneration power output from $1.35 \mathrm{~kW}$ to $1.5 \mathrm{~kW}$.

For demonstration purposes only, at $t=482 \mathrm{~s}$ the microgeneration control was disabled and the units increase their power as in the beginning of the experiment. In order to compensate the resulting voltage increase, the EV charger increases its power consumption to $2 \mathrm{~kW}$. When the network load increases at $t=606 \mathrm{~s}$, the phase voltage returns to $232 \mathrm{~V}$ and the EV charging power reduces to the nominal power $1.5 \mathrm{~kW}$.

This experiment validates the voltage control strategies proposed in REIVE and shows the effectiveness of the coordination between local control strategies and centralized algorithms. This coordinated control will avoid the need of implementing complex algorithms at the DTC and reduces the dependence of the management system from the communication infrastructure in the event of communication delays or failures.

\section{Conclusions}

Results from the Portuguese SG projects InovGrid and REIVE support the effectiveness of the architectures, functionalities and exploited business cases, showing that a nationwide rollout would create value for society. Presently, these initiatives are being 
extended to other municipalities in order to test different technologies and to validate the concepts in areas with different socioeconomic and network characteristics.

Additionally, InovGrid and REIVE contributed to align the Portuguese DSO strategy with the European 2020 Energy objectives. Their holistic approach to the different involved players allowed the development of business models that will contribute to reduce $\mathrm{CO}_{2}$ emissions, integrate more renewables and promote energy efficiency.

The relevance of these projects was in fact recognized by several international entities. As an example, the Joint Research Centre Institute for Energy and Transport from the European Commission and Eurelectric, in 2011, selected InovGrid as the single case study for testing and validation of the Electric Power Research Institute business case assessment methodology. Following this selection, InovGrid is proposed to receive the "Core Project" label from the European Electricity Grid Initiative EEGI, being one of the four projects that achieved it so far.

\section{References}

[1] Technology Roadmap Smart Grids, International Energy Agency (IEA), 2011.

[2] N. Hatziargyriou, N. Jenkins, G. Strbac, J.A. Peças Lopes, J. Ruela, A. Engler, J. Oyarzabal, G. Kariniotakis, A. Amorim, Microgrids - Large Scale Integration of Microgeneration to Low Voltage Grids, CIGRE, 2006.

[3] A.G. Madureira, J.C. Pereira, N.J. Gil, J.A. Peças Lopes, G.N. Korres, N.D. Hatziargyriou, Advanced control and management functionalities for multimicrogrids, Eur. Trans. Electr. Power 21 (2) (2011) 1159-1177.

[4] D. Rua, et al., Advanced metering infrastructure functionalities for electric mobility, in: Innovative Smart Grid Technologies Conference Europe (ISGT Europe), 2010 IEEE PES, Octber 2010, pp. 1-7.

[5] P. Matos, et al., Inovgrid, A Smart vision for A next generation distribution system, cired 2013, Stockholm, Sweden, June 2013.

[6] F.J. Soares, et al., Evaluating the impacts of electric vehicles and microgeneration in distribution networks, presented at the SMARTGREENS 2012, Vila Nova de Gaia, Portugal, 2012.

[7] MICROGRIDS and MOREMICROGRIDS Projects. Available at: http://www. microgrids.eu/
[8] A.G. Madureira, et al., Coordinated voltage support in distribution networks with distributed generation and microgrids, IET Renew. Power Generation 3 (December (4)) (2009) 439, 454

[9] R.J. Bessa, A. Trindade, A. Monteiro, V. Miranda, C.S.P. Silva, Solar powe forecasting in smart grids using distributed information, in: PSCC 2014 - 18th Power Systems Computation Conference, Wroclaw, Poland, August 2014.

[10] J.A. Peças Lopes, et al., Defining control strategies for MicroGrids islanded operation, IEEE Trans. Power Syst. 21 (May (2)) (2006) 916, 924.

[11] L.C. Moreira, et al., Using low voltage MicroGrids for service restoration, IEEE Trans. Power Syst. 22 (February (1)) (2007) 395-403.

[12] F.J. Soares, et al., Quasi-real-time management of electric vehicles charging, Electric Power Syst. Res. 108 (March) (2014) 293-303.

[13] J.A.P. Lopes, et al., Integration of electric vehicles in the electric power system, Proc. IEEE 99 (2011) 168-183.

[14] P.C. Baptista, C.M. Silva, J.A. Peças Lopes, F.J. Soares, P.R. Almeida, Evaluation of the benefits of the introduction of electricity powered vehicles in an island, Energy Convers. Manage. 76 (December) (2013) 541-553.

[15] J.A. Peças Lopes, et al., Using vehicle-to-grid to maximize the integration of intermittent renewable energy resources in islanded electric grids, in: International Conference on Clean Electrical Power, Capri, Italy, June 9-11, 2009, pp. 290-295.

[16] P.R. Almeida, J.P. Lopes, F.J. Soares, M.H. Vasconcelos, Automatic generation control operation with electric vehicles, in: Bulk Power System Dynamics and Control (iREP) - VIII (iREP), 2010 iREP Symposium, 2010, pp. 1-7.

[17] T. Stetz, et al., Improved low voltage grid-integration of photovoltaic systems in Germany, IEEE Trans. Sustain. Energy 4 (April (2)) (2013) 534, 542.

[18] J. Miguel Rodrigues, et al., Using photovoltaic systems to improve voltage control in low voltage networks, in: ISGT2012 - Third IEEE PES Innovative Smart Grid Technologies Europe Conference, Berlin, Germany, October 2012.

[19] Python Software Foundation. Python Language Reference. Available at http://www.python.org

[20] R.J. Bessa, et al., Optimized bidding of a EV aggregation agent in the electricity market, IEEE Trans. Smart Grid 3 (March (1)) (2012) 443-452.

[21] D. Rua, L.F. Pereira, N. Gil, J.A. Peças Lopes, Impact of multi-microgrid communication systems in islanded operation, in: Innovative Smart Grid Technologies Conference Europe (ISGT Europe), IEEE PES, Manchester, UK, December, 2011.

[22] ns-3, A discrete-event network simulator. Available at http://www.nsnam.org

[23] F. Ribeiro, et al., PACE Simple Multi-hop Scheduling for Single-radio 802.11based Stub Wireless Mesh Networks, October 2013.

[24] R.J. Ferreira, et al., A new bi-directional charger for vehicle-to-grid integration, in: 2nd IEEE PES International Conference and Exhibition on Innovative Smart Grid Technologies (ISGT Europe), December 2011. 